\title{
The Influence of Chemical Composition on LNG Pool Vaporization
}

\author{
Zhidong $\mathrm{Yu}^{*}$ \\ China Academy of Railway Sciences, Beijing, 100081, China \\ Corresponding Email: yygdupt_mmc@163.com
}

\begin{abstract}
A model is used to examine the influence of chemical composition on the vaporization rate of $\mathrm{LNG}$ during spreading. Calculations have been performed whereby the vaporization rate of the LNG mixtures has been compared to the vaporization of pure methane under the initial conditions. The detailed results indicate that the vaporization rate LNG mixture is different to that of pure methane. LNG as the liquid mixture gets rich in ethane and isobaric latent heat increases rapidly, leading to the rate vaporization of LNG decrease in compared to pure methane.
\end{abstract}

\section{Introduction}

The volume of liquefied natural gas (LNG) is only 1/600 that of its gaseous state, LNG allows more flexible means of transport and storage. In recent years demand for natural gas as a fuel has been on the increase. World-wide requirements necessitate long distance marine and tail transportation. Such an increase will bring renewed pressures on improved quantification of risk associated with LNG transport and loading operations, ensuring that safety precautions can be put in place [1] .

It is the most importance to understand and quantify the physical processes which take place in the spillage of LNG. In modeling the consequences of releases of LNG, the quantities of interest for the rate at which vapour is produced from the pool, the size of the pool, and the temperature of the vapour $[2,3]$.

\section{Mathematic model analysis}

\subsection{Pool spreading model}

We can describe the spreading of pool to give the surface area, which is an important variable in vaporization rate calculation. Different equations are used to calculate the pool radius depending upon whether the spill is on land or water, and whether it is an instantaneous, a continuous [4-6] .

The radius of a pool spreading on land is found by numerically integrating the spreading rate equation:

$$
\frac{d r}{d t}=\sqrt{2 g\left(h-h_{\min }\right)}
$$

Where $r$ is the pool radius

$\mathrm{t}$ is the time from the start of release $(\mathrm{s})$

$\mathrm{g}$ is the acceleration due to gravity

$\mathrm{h}$ is the pool thickness

$\mathrm{h}_{\min }$ is a minimum pool thickness

This assumes that the driving force for the spread is formed by the hydrostatic difference between the thickness of the current liquid layer and a minimum pool thickness characteristic for the substrate. This results in the rate of spreading decreasing as the pool approaches the minimum thickness.

The spreading of liquids on water is found by a three-regime model. Each regime is dominated by the balance of two main forces, the regimes occurring sequentially. The first regime to occur is the gravity-inertia regime when the gravity spreading and inertial forces are approximately equal. This is followed by the gravity-viscous regime when the gravity spreading and viscous drag forces are approximately equal. For non-volatile liquids which may spread to form thin slicks there may then be a third regime, the viscous-surface tension regime, where the viscous drag and surface 
tension forces are approximately equal. In practice, with the minimum thickness criterion implemented in the model the viscous-surface tension regime is rarely encountered.

The four forces considered in the three regimes are:

Gravity spreading force

$$
F_{G}=M_{\text {pool }}\left(\frac{g h \Delta}{r}\right)
$$

Inertial force

$$
F_{1}=-M_{\text {pool }} \frac{d^{2} r}{d t^{2}} \cong M_{\text {pool }} \frac{r}{2 t^{2}}
$$

Viscous drag force

$$
F_{D}=\pi r^{2} \mu_{w}\left(\frac{r}{t}\right)\left(\frac{\rho_{w}}{\mu_{w} t}\right)^{\frac{1}{2}}
$$

Surface tension force

$$
F_{S}=2 \pi r \sigma
$$

In the equations above $\Delta=\left(\rho_{\mathrm{w}}-\rho_{\mathrm{L}}\right) / \rho_{\mathrm{w}}$ is a relative density factor, with $\rho_{\mathrm{w}}, \rho_{\mathrm{L}}$ being the liquid and water densities $\left(\mathrm{kg} / \mathrm{m}^{3}\right)$. Furthermore $\mu_{\mathrm{w}}$ is the dynamic viscosity of the water $\left(\mathrm{kg} / \mathrm{m} / \mathrm{s}\right.$, and $\sigma=\sigma_{\mathrm{wa}}-\sigma_{\mathrm{La}}-\sigma_{\mathrm{Lw}}$ is the net surface tension $(\mathrm{N} / \mathrm{m})$, with $\sigma_{\mathrm{wa}}, \sigma_{\mathrm{La}}, \sigma_{\mathrm{Lw}}$ being the surface tension of water-air, liquid-air, liquid-water, respectively.

\section{2 instantaneous spills model}

The radius is given as follows.

In the gravity-inertia regime when $0<\mathrm{t}<\mathrm{t}_{1}$ by:

In the gravity-viscous regime when $\mathrm{t}_{1}<\mathrm{t}<\mathrm{t}_{2}$ by:

$$
r(t)=K_{10}\left(\frac{g \Delta}{\rho_{L}}\right)^{1 / 4} M_{p o o l}^{1 / 4}(O) t^{1 / 2}
$$

$$
r(t)=K_{20}\left(\frac{g \Delta}{\rho_{L}^{2}\left(\mu_{w} / \rho_{w}\right)^{1 / 2}}\right)^{1 / 6} M_{\text {pool }}^{1 / 3}(0) t^{1 / 4}
$$

In the viscous-surface tension regime when $\mathrm{t}>\mathrm{t}_{2}$ by:

$$
r(t)=\left(\frac{4 \sigma^{2}}{\rho_{w} / t_{w}}\right)^{1 / 4} t^{3 / 4}
$$

The transition from the gravity-inertia to the gravity-viscous regime occurs at the time:

$$
t_{1}=\left(\frac{K_{20}}{K_{10}}\right)^{4}\left(\frac{\rho_{w} M_{p o o l}(\mathrm{O})}{\rho_{L} g \mu_{w} \Delta}\right)^{1 / 3}
$$

and from the gravity-viscous to the viscous-surface tension regime at the time:

$$
t_{2}=\left(K_{20}\right)^{2}\left(\frac{M_{p o o l}^{2}(0) g \mu_{w} \Delta}{\rho_{w} \rho_{L}^{2}}\right)^{1 / 3}\left(\frac{\rho_{w}}{2 \sigma}\right)
$$

\subsection{Continuous spills model}

The case of a constant spillage $\mathrm{S}(\mathrm{t})=\mathrm{S}$ is considered. The radius is given as follows.

In the gravity-inertia regime when $0<\mathrm{t}<\mathrm{t}_{3}$ by:

$$
r(t)=K_{11}\left(\frac{g \Delta}{\rho_{L}}\right)^{1 / 4} S^{1 / 4} t^{3 / 4}
$$

In the gravity-viscous regime when $\mathrm{t}>\mathrm{t}_{3}$ by:

$$
r(t)=K_{21}\left(\frac{g \Delta}{\left(\mu_{w} / \rho_{w}\right)^{1 / 2} \rho_{L}^{2}}\right)^{1 / 6} S^{1 / 3} t^{7 / 12}
$$

The transition between these regimes occurs at the time:

$$
t_{3}=\left(\frac{K_{21}}{K_{11}}\right)^{6}\left(\frac{\rho_{w}}{\rho_{L} g \Delta \mu_{w}} S\right)^{1 / 2}
$$

For a continuous spill the viscous-surface tension phase occurs simultaneously with the gravity-viscous phase rather than following it in time, with the part of the slick that is spreading in the gravity-viscous phase supplying the mass for that part in the viscous-surface tension phase. No transition to the viscous-surface tension phase is made for continuous spills. 
In the above equations $\mathrm{K}_{10}, \mathrm{~K}_{11}, \mathrm{~K}_{20}, \mathrm{~K}_{21}$ are dimensionless constants. conducted experiments specifically designed to test the validity of the above pool spread model and to determine the values for the constants $\mathrm{K}_{10}, \mathrm{~K}_{11}, \mathrm{~K}_{20}$ and $\mathrm{K}_{21}$. their recommended vlues which have been implemented here are shown inTable 1.

Table 1. Constants in pool-spreading models.

\begin{tabular}{|l|l|}
\hline constant & value \\
\hline $\mathrm{K}_{10}$ & 1.53 \\
\hline $\mathrm{K}_{20}$ & 1.21 \\
\hline $\mathrm{K}_{11}$ & 1.24 \\
\hline $\mathrm{K}_{21}$ & 1.09 \\
\hline
\end{tabular}

\subsection{Pool vaporization model}

The liquid spill model can describe the spreading and vaporization of pools of liquid spilt either on land or water. For spills on land the model takes into account heat conduction from the ground, ambient convection from the air, radiation and vapour diffusion. These are usually the main mechanisms for boiling and evaporation. Solution and possible reaction of the liquid in water are also included for spills on water, these being important for some chemicals. These are modeled numerically, maintaining mass and heat balances for both boiling and evaporating pools. This allows the pool temperature to vary as heat is either absorbed by the liquid or lost during evaporation $[7,8]$.

At each time step in the numerical calculations the heat balance on the pool is evaluated and from this the vaporization mechanism, vaporization rate and pool temperature are determined.

Initially, the temperature $T_{\text {pool }}$ of the pool is assumed to be equal to the temperature $T_{\text {spill }}$ of the spilled liquid. The net rate of heat flow into the pool is calculated from

$$
Q_{\text {net }}=Q_{\text {cond }}+Q_{\text {conv }}+Q_{\text {rad }}+Q_{\text {sol }}+Q_{\text {spill }}-Q_{\text {evap }}
$$

Where $\mathrm{Q}_{\text {cond }}$ is the heat flow rate from conduction $(\mathrm{W})$
$\mathrm{Q}_{\text {conv }}$ is the heat flow rate from convection (W)
$\mathrm{Q}_{\mathrm{rad}}$ is the heat flow rate from solar radiation (W)
$\mathrm{Q}_{\text {sol }}$ is the heat flow rate from dissolution (W)
$\mathrm{Q}_{\text {spill }}$ is the heat flow rate from spilled liquid (W)
$\mathrm{Q}_{\text {evap }}$ is the heat flow rate from evaporation (W)

\subsection{Multi-component pool model}

In order to account for real mixture behaviour, the model keeps track of the pool inventory at all times and employs established mixing rules to estimate overall pool properties. As in the single-component model two limiting cases in pool vaporization are distinguished: boiling and evaporation. The multi-component pool model is able to predict the evaporation rate and phase composition from both types of pool vaporization. Additionally, the model makes continuous checks for transitions between boiling and evaporation regimes, by performing a bubble point calculation at each step [9] .

The pool model described assumes ideal mixing of the components within the liquid pool components. The muticomponent pool model is formulated from the following equations.

Spreading law:

For pools on land:

For pools on water:

$$
\frac{d r}{d t}=\sqrt{2 g\left(h-h_{\min }\right)}
$$

$$
r=f\left(M_{\text {spill }}(\mathrm{O}), S(t), t\right)
$$

Mass balance per component $i(i=1,2, \ldots, n$; when $n$ is the number of components):

$$
\frac{d M_{\text {pool }}}{d t}=S_{i}(t)-E_{\text {vap }}^{i}(t)-E_{\text {sol }}^{i}(t)
$$

Cumulative mass dissolved per component $\mathrm{i}(\mathrm{i}=1,2, \ldots, \mathrm{n})$ :

$$
\frac{d M_{v a p}^{i}}{d t}=E_{v a p}^{i}(t)
$$

Cumulative mass dissolved per component $\mathrm{i}(\mathrm{i}=1,2, \ldots, n)($ only for pools on water):

$$
\frac{d M_{s o l}^{i}}{d t}=E_{s o l}^{i}(t)
$$

Energy balance: 


$$
\frac{d T_{\text {pool }}}{d t}=\frac{\left\{Q_{i n}+S(t) C_{p l}^{\text {spill }}\left(T_{\text {spill }}\right)\left[T_{\text {spill }}-T_{\text {pool }}\right]\right\}}{C_{p l}^{\text {pool }}\left(T_{\text {pool }}\right) M_{\text {pool }}}-\frac{\left.\left.\left\{E_{\text {vap }}(t) \sum_{i=1}^{n} Y_{\text {vap }}^{i}\right\rceil H_{\text {vap }}^{i}\left(T_{\text {pool }}\right)-E_{\text {sol }}(t) \sum_{i=1}^{n} X_{\text {sol }}^{i}\right\rceil H_{\text {sol }}^{i}\left(T_{\text {pool }}\right)\right\}}{C_{p l}^{\text {pool }}\left(T_{\text {pool }}\right) M_{\text {pool }}}
$$

where, $\mathrm{M}_{\text {pool }}{ }^{\mathrm{i}}$ is the mass in the pool of component $\mathrm{i}(\mathrm{kg}) \mathrm{S}_{\mathrm{i}}(\mathrm{t})$ is the mass spill rate of component $\mathrm{i}$ which is equal to 0 for Instantaneous spills $(\mathrm{kg} / \mathrm{s})$

$E_{\text {vap }}{ }^{i}(t)$ is the vaporization rate of component $i(\mathrm{~kg} / \mathrm{s})$

$\mathrm{E}_{\mathrm{sol}} \mathrm{i}(\mathrm{t})$ is the dissolution rate of component $\mathrm{i}$ only applicable or pools on water $(\mathrm{kg} / \mathrm{s})$

$\mathrm{Q}_{\text {in }}$ sum of the heat inputs to the pool = sum of heat of conduction $(J)$

$\mathrm{Q}_{\text {cond, }}$ convection $\mathrm{Q}_{\text {conv }}$ and radiation $\mathrm{Q}_{\mathrm{rad}}(\mathrm{J})$

$\mathrm{C}_{\mathrm{pL}}{ }^{\text {spill }}\left(\mathrm{T}_{\text {spill }}\right)$ is the specific liquid heat capacity at the temperatureand composition of the spill $(\mathrm{J} / \mathrm{kg} / \mathrm{k})$

$\mathrm{C}_{\mathrm{pL}}{ }^{\text {pool }}\left(\mathrm{T}_{\text {pool }}\right)$ is the specific liquid heat capacity at the temperature and composition of the pool $(\mathrm{J} / \mathrm{kg} / \mathrm{k})$

$\Delta \mathrm{H}_{\text {vap }}{ }^{\mathrm{i}}\left(\mathrm{T}_{\text {pool }}\right)$ is the heat of vaporization of component $\mathrm{i}$ at the temperatureof the pool $(\mathrm{J} / \mathrm{kg})$

$\Delta \mathrm{H}_{\text {sol }}{ }^{\mathrm{i}}\left(\mathrm{T}_{\mathrm{pool}}\right)$ is the heat of dissolution of component $\mathrm{i}$ at the temperature of the pool only applicable for pools on water $(\mathrm{J} / \mathrm{kg})$

$Y_{\text {vap }}{ }^{i}$ is the mass fraction of component $i$ in the vaporization rate (fraction)

$\mathrm{X}_{\mathrm{sol}}{ }^{\mathrm{i}}$ is the mass fraction of component $\mathrm{i}$ in the vaporization rate (fraction)

\section{Simulating analysis}

A number of simulations were performed, by means of the PHAST model outlined above, in order to ascertain how the rate of vaporization of LNG is different to that of pure methane under identical spill conditions. In each simulation run the initial LNG mixture is modeled as consisting of $90 \%$ methane and $10 \%$ ethane which can be considered as a reasonable representation of a typical LNG composition. The LNG mixture was assumed to be at -162 when released, the pressure was taken as atmospheric, while the water temperature is assumed to be $300 \mathrm{~K}$ throughout the simulation run. A number of simulations were run for LNG and methane released on land or water. No qualitative differences between methane and LNG were observed as a function of the mass released, and therefore all the results reported below are based on the release of $50 \mathrm{~m}^{3}$ tank of $\mathrm{LNG}$ and methane.

\subsection{Case 1}

Simulating LNG and methane spill on land. In the scenario it was assumed that calm atmospheric conditions prevail during the pool spreading and vaporization. LNG and methane volume are 50 cubic meters; Leak size is $100 \mathrm{~mm}$; Wind velocity is $1 \mathrm{~m} / \mathrm{sec}$ and the atmospheric stability is class G.

In the scenario, curve labeled LNG in the initial stages of the spill no marked difference is observed between the vaporization of pure methane. The rate of vaporization of LNG is higher than that of methane. The difference in the vaporization rate is approximate $8 \%$, as illustrated in Figure 1 and Figure 2.This is primarily due to the unusual shape of the vapour-liquid phase envelope for the methane-ethane mixture. As the LNG liquid becomes ethane-rich, the total latent heat exhibits a rapid increase. This is due to a combination of the direct and indirect differential latent heat.

Therefore the influence of chemical composition on the rate of LNG vaporization is important. The increase of the latent heat leads to a substantial decrease of the rate of vaporization.

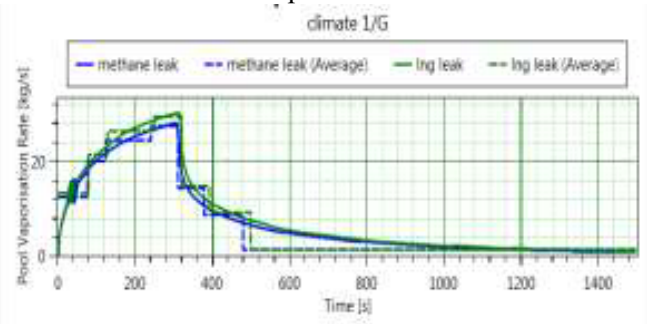

Fig. 1. Pool vaporization rate vs time on land.

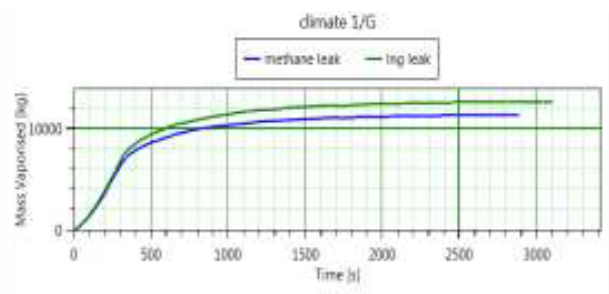

Fig. 2. Mass vaporized vs time on land. 


\subsection{Case 2}

Simulating LNG and methane spill on water. In the scenario it was assumed that calm atmospheric conditions prevail during the pool spreading and vaporization. Wind velocity is $1 \mathrm{~m} / \mathrm{sec}$ and the atmospheric stability is class G.

In the scenario, the rate of vaporization of methane is smaller than that of LNG. The difference in the vaporization rate on water is bigger than the vaporization rate on land. This in turn leads to a partial decrease in the vaporization rate, since the amount of heat transferred from the water surface into the pool decreases due to a decrease in the temperature difference driving force. as illustrated in Figure 3 and Figure 4.

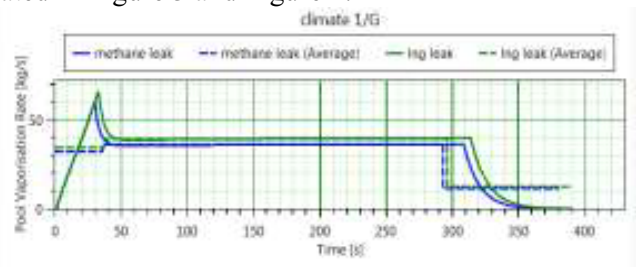

Fig. 3. Pool vaporization rate vs time on water.

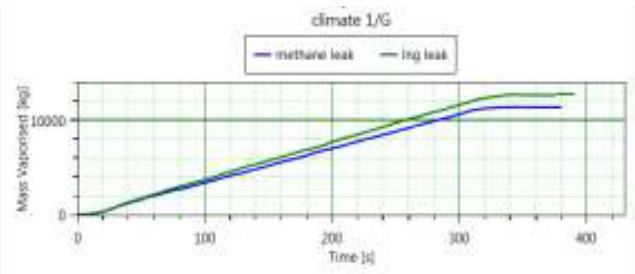

Fig. 4. Mass vaporized vs time on water.

\section{Conclusions}

The results indicate, the vaporization rate of LNG is different to that of pure methane. The difference can be attributed to the influence of chemical composition. For LNG gets rich in ethane, leading to a large decrease in the vaporization rate of LNG compared to pure methane. The overall results suggest that as the vaporization rate treating a pure methane spill results as an LNG spill in underestimation of approximate of $8 \%$.

\section{Acknowledgements}

This Project is supported by the china railway corporation Science research Foundation of China, No.2016X007-F.

\section{References}

1. R.P. Koopman, D.L. Ermak: Lessons learned from LNG safety research. Journal of Hazardous Materials, 140, (2007), p.412-428.

2. M.J. Ivings, C.J. Lea, D.M. Webber: A protocol for the evaluation of LNG vapour dispersion models. Journal of Loss Prevention in the Process Industries, 26(1), (2013), p. 153-163.

3. T.A. Melton, J.B. Cornwell: LNG trench dispersion modeling using computational fluid dynamics. Journal of Loss Prevention in the Process Industries, 23(6), (2010), p. 762-767.

4. F. Gavelli, M.K. Chernovsky, E. Bullister: Modeling of LNG spills into trenches, Journal of Hazardous Materials, 180(1-3), (2010), p. 332-339.

5. H.A. Luketa: A review of large-scale LNG spills: experiments and modeling. Journal of Hazardous Materials, 132 , (2006), p. 119-140.

6. J.A. Havens, T.O. Spicer: LNG vapor cloud exclusion zones for spills into impoundments. Process Safety Progress, 24(3), (2005), p. 181-186.

7. O. R. Hanna, F. Gavelli, M. Ichard: Validation of FLACS against experimental data sets from the model evaluation database for LNG vapor dispersion. Journal of Loss Prevention in the Process Industries, 23(6), (2010), p. 857-877.

8. J.A. Havens, T.O. Spicer: Wind tunnel studies of LNG vapor dispersion from impoundment, AIChE National Spring Meeting, Houston.

9. R. Bubblco, E. Salzano: Acoustic analysis of blast waves produced by rapid phase transition of LNG released on water, Safety Science, 47, (2009), p. 515-521. 